\title{
Analysis and Diagnostic Tools to Improve Governance in The Context of Urban Planning and Territorial Management
}

1 General Direction of Territory and Habitation of the Region of Murcia (Spain), gloria.martinez3@carm.es.

2 Technical University of Cartagena, UPCT (Spain); gloria.martinez@upct.es.

\begin{abstract}
:
The Region of Murcia (Spain) has participated in the period 2008-2013, together with other regions of the Mediterranean area, in several European research projects financed with ERDF funds. These projects aim to propose methodologies and tools for improving the governance of urban and regional planning. Phenomena such as land consumption, changing in land uses or policies of territorial specialization planned by the government are essential for the balanced development of regions and cities. The results of these investigations have now materialized in new analysis and diagnostic methodologies in order to improve political governance in management and land use planning, and how to achieve a more sustainable development of our cities.

This paper presents the results of one of these projects, called OSDDT, through territorial indicators and urban operational tools. The implementation of these new elements in the current sectoral legislation will allow generating new methods of study in urban and regional planning.
\end{abstract}

Keywords: GIS tools, urban planning, urban operational tools, territorial indicators, territorial management.

\section{Introduction}

The objective of this study is to test the indicators obtained in the European research OSDDT project in a specific case. Specifically, we will estimate the goodness of the instrument called Río Mula, Vega Alta and Eastern Territorial Management Plan when regulating and controlling the urbanization and building processes in a specific area, called agrofluvial, area of unique landscape characteristics and of great agronomic value in the territory of the Region of Murcia.

For this reason, the fertile soil consumption index will be calculated to quantify the presence of current buildings and infrastructures on protected land and a simulation with the restrictions imposed by the aforementioned standard. This index belongs to the first family of indicators: amount of land consumption, classified by typologies.

In this way we can compare the values and see if the standard meets the desired objectives or not.

\section{Area of study}

The scope of action set is the space that is contained in the limit marked by the polygons present in the protection agro fluvial shape and located within the municipal term of Mula on the undeveloped and developable land without sectoring.

To carry out the simulation, the Plot has been chosen as the work unit. The definition of Parcel of the rustic cadaster cartography is the following:

Plot: It is the portion of land of the same nature, nestled in a municipal area and closed by a polygonal line that delimits, for this purpose, the spatial scope of the property right of 
an owner or of several undivided properties and, where appropriate, the constructions located in this area, whatever their owner, and regardless of other rights that fall on the property.

Regarding the polygon as a whole, it is the extension of land, public domains or others that generate an enclosure with a surface that can be represented in plane and defined property. They are labelled in the scope of the polygon with the series of natural numbers in a maximum of five digits.

For the exclusive cadastral purposes, the parcel or portion of land of the same nature, located in a municipal area and closed by a polygonal line that delimits, for such purposes, the spatial scope of the property right of a owner or several undivided properties and, where appropriate, the constructions located in said area, whatever their owner, and regardless of other rights that fall on the property. (Article 6, RDL 1/2004 Consolidated Text)

Each real estate will be assigned a cadastral reference as identifier, consisting of an alphanumeric code that allows it to be unequivocally located in the official Cadastral cartography (article 6, RDL 1/2004 Consolidated Text).

\section{Methodology}

The simulation area is determined as the Agro-Fluvial Protection Zone. Several protected polygons are distinguished according to this figure, but we will focus on the municipality of Mula. The polygon that delimits the agro-Fluvial zone includes the urban land of the municipality of Mula, so it is necessary to eliminate the soils where this protection figure does not apply.

The "Fertile soil consumption" index is calculated as follows:

$$
\text { Fertile soil consumption } \%=(\text { Urbanized area } / \text { reference area }) * 100(\%)
$$

Where:

Urbanized area $=$ infrastructure + buildings

Reference area $=$ municipal area

\subsection{Current situation:}

The reference area used to calculate this index is the total area occupied by the typologies of undeveloped and urban land without sectorization of the municipality of Mula and that are contained within the limits of the figure 1.

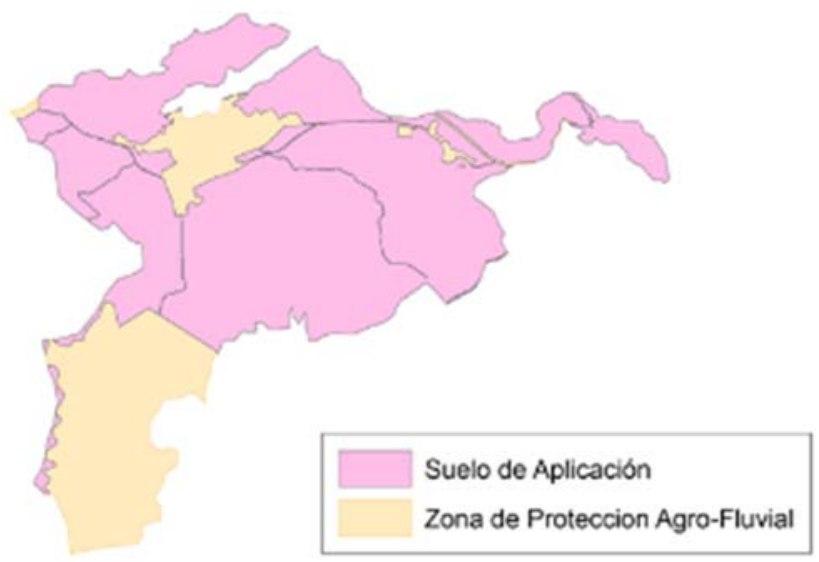

Figure 1. Agro-Fluvial Land protection figure 
- $\quad$ Fertile Land = Agro-Fluvial Land Area classified as undeveloped or developable without sectorization $=27.419 .300 \mathrm{~m}^{2}\left(27,4193 \mathrm{~km}^{2}\right)$.

- $\quad$ Builded surface $=$ we found in the rustic cadastre cartography a layer of geographic information with each of the constructions in this area. In this layer it is differentiated according to the type of construction.

The total built area within the scope of action is: Constructed area $=453.068,32 \mathrm{~m}^{2}$ $\left(0,45 \mathrm{~km}^{2}\right)$.

Fertile soil consumption $\%=(423.544,6 / 27.419 .300) * 100(\%)=1,65 \%$

\subsection{Simulation:}

Now we will carry out a simulation, with another hypothesis based on the Territorial Management Plan, in this hypothesis the built surface differs, which we must estimate:

Potentially Consumed Land = Maximum area of possible construction and / or transformation.

For a correct implementation of the simulation we have to calculate the potentially buildable area. To calculate this area, the following actions have been carried out:

1. Elimination of the fictitious plots 09000: Since the parcels that have the field PLOT = '09000' do not actually exist and must be ignored according to the Descriptive Manual of the Land Registry.

2. Elimination of plots of Public Domain: Public domain plots have been removed. The reason for this is that by its definition in the descriptive manual of cadastral information it is understood that it cannot be built (and / or modified) on them.

3. Selection of plots with access from the road: According to article 144, section 5.b.4, the new buildings must comply with the requirement of "being built on a plot that has road access from existing public roads ..." This is the requirement that must be taken as a starting point to make the selection of plots susceptible to action. Here it should be noted that there is no official mapping of road axes (in the cadastre there are only axes for urban cartography), so to carry out this action the road layer of the sigpac has been used.

4. Elimination of plots that have a depth of at least $15 \mathrm{~m}$ : In article 144: Applicable Regime, section 5.b.4 it is specified that buildings for residential use must meet the requirement of "Be executed on a plot that has vehicular access from existing publicly owned roads, and must be set back in relation to the axis of the same at least 15 meters ".

5. Elimination of plots that do not have 20 meters of frontage: In Art.144: Applicable Regime, section 5.b.5 it is specified that "In order to establish visual windows, at least twenty meters from the front of the plot that leads to a free public road path must be preserved of any building or construction of private ownership up to the bottom of the affected parcel."

6. Mergers of the area of scattered and already built plots to calculate the area already built and if it involves a built area greater than $5 \%$.

7. Elimination of plots outside the scope of action: The plots that are not included in the typology of non-unbailable land, developable land without sectoring or without programming have been eliminated according to the Mula planning, since it is in this 
type of land where the figure of protection of Agro-Fluvial Soil is applied. This has 1 meant eliminating the MULA urban area from the simulation.

At the end of all these processes, the plots that are potentially buildable have been ob- 3 tained and the maximum buildable area is calculated. The total resulting potentially buildable area would be:

Maximum buildable area $=1.366 .028,02 \mathrm{~m}^{2}$

$$
\text { Fertile soil consumption } \%=(1.366 .028,02 / 27.419 .300) * 100(\%)=4,98 \%
$$

This indicates that if it were built on the total surface area on which the new norm allows it, the Fertile Soil Consumption index would be $4.98 \%$.

However, it would be unlikely that residential-type buildings would be constructed in the whole potentially buildable area, so various estimates are made in Table 1.

Table 1. Variation of the consumption indicator.

\begin{tabular}{cccc}
\hline Maximum buildable area & $\mathbf{\%}$ & $\mathbf{m}^{2}$ & Fertile Soil Consumption \\
\hline $1.366 .028,02$ & 75 & $1.024 .521,02$ & $3,74 \%$ \\
$1.366 .028,02$ & 50 & $683.014,02$ & $2,49 \%$ \\
$1.366 .028,02$ & 25 & $341.507,01$ & $1,24 \%$ \\
\hline
\end{tabular}

\section{Results and Conclusions}

The regulations of the Guidelines and Territorial Management Plan of the Mula River, Vega Alta y Oriental limits the occupation of the constructions of the plots located in agro-fluvial protection soils in less than $5 \%$ of the total area of the area delimited. This limitation is considered to fulfill the objective of preserving the values of quality and high fragility of the traditional landscape of the river valleys.

However, it is reasonable to think that it is unlikely that residential-type buildings would be built on the entire potentially buildable area, therefore estimates could be made that would reduce consumption, and it is at this point where future modifications of the plan can influence to reduce consumption.

Funding: This research was funded by European Med program 2007-2013.

Acknowledgments: Zaida Hernández Guillen for her technical support.

Conflicts of Interest: The authors declare no conflict of interest.

\section{References}

1. Otremed, OSDDT and Pays Med Urban: European Med program 2007-2013. CTE 0, axes 2 \& 4. 2nd call - classical projects, 2009. www.sdimed.eu, www.osddt.eu and www.paysmed.net

2. Directive 2007/2/EC of the European Parliament and of the Council of 14 March 2007 establishing an Infrastructure for Spatial Information in the European Community (INSPIRE)

3. Sitmurcia - Sistema de Información Territorial de la Región de Murcia. Consejería de Obras Públicas y Ordenación del Territorio de la Region de Murcia. www.sitmurcia.es

4. Directrices y Plan de Ordenación Territorial de la Comarca del Río Mula, Vega Alta y Oriental. Comunidad Autonoma de la Región de Murcia.http://www.carm.es/web/integra.servlets.Blob?archivo=detor.pdf\&tabla=archivos\&campoclave=idarchivo\&valorclave $=61468 \&$ campoimagen $=$ archivo\&idtipo $=60 \&$ rastro $=c 217 \$ \mathrm{~m} 2594,24302$

5. Región de Murcia. Infraestructura de Datos Espaciales de Referencia de la Región de Murcia. www.cartomur.imida.es/ 